\title{
Clathrate guest atoms under pressure
}

\author{
M. Christensen, ${ }^{1}$ S. Johnsen, ${ }^{1}$ F. Juranyi, ${ }^{2}$ and B. B. Iversen ${ }^{1, a)}$ \\ ${ }^{1}$ Center for Energy Materials, Department of Chemistry and iNANO, University of Aarhus, DK-8000 Aarhus \\ C, Denmark \\ ${ }^{2}$ Laboratory for Neutron Scattering, Paul Scherrer Institute and ETH Zürich, CH-5232 Villingen, \\ Switzerland
}

(Received 24 November 2008; accepted 10 February 2009; published online 6 April 2009)

\begin{abstract}
Powder inelastic neutron scattering (INS) has been used to determine the guest atom "rattling" energy in thermoelectric clathrates $\mathrm{Ba}_{8} Y_{x} \mathrm{Ge}_{46-x}\left(Y_{x}=\mathrm{Ni}_{6}, \mathrm{Cu}_{6}, \mathrm{Zn}_{8}, \mathrm{Ga}_{16}\right)$ under different applied conditions. Chemical pressure was exerted by the atomic substitution, and a physical pressure of 9 kbars was applied using a clamp cell. The volume reduction induced by the physical pressure increases the energy of the guest atom rattling mode, but the local chemical environment in the cage also appears to have a similar effect. The guest atom energies were investigated as function of temperature, and softening of the guest atom modes was observed upon cooling the sample. $\mathrm{Ba}_{8} \mathrm{Ga}_{16} \mathrm{Ge}_{30}$ with holes ( $p$-type) and electrons ( $n$-type) as charge carriers reveal similar temperature behavior, suggesting anharmonic potentials of similar shape for the Ba guest atom independent of the charge carrier type. For $\mathrm{Sr}_{8} \mathrm{Ga}_{16} \mathrm{Ge}_{30}$ a much stronger anharmonic potential was observed compared with $\mathrm{Ba}_{8} \mathrm{Ga}_{16} \mathrm{Ge}_{30}$. The guest atom energies for $\mathrm{Ba}_{8} Y_{x} \mathrm{Ge}_{46-x}\left(Y_{x}=\mathrm{Ni}_{6}, \mathrm{Cu}_{6}, \mathrm{Zn}_{8}\right)$ extracted from powder INS were compared with Einstein energies obtained from atomic displacement parameters determined from multitemperature single crystal x-ray diffraction. Additionally, the $\mathrm{Ba}_{8} Y_{x} \mathrm{Ge}_{46-x}\left(Y_{x}=\mathrm{Ni}_{6}, \mathrm{Cu}_{6}, \mathrm{Zn}_{8}\right)$ samples were characterized with respect to their thermoelectric properties. (C) 2009 American Institute of Physics. [DOI: 10.1063/1.3099589]
\end{abstract}

\section{INTRODUCTION}

Improved thermoelectric devices for cooling and power generation may in the future play an important role for the refrigeration industry and waste heat recovery. ${ }^{1}$ The dimensionless thermoelectric figure of merit is defined as $z T$ $=T S^{2} \sigma / \kappa$, where $T$ is the temperature, $S$ is the Seebeck coefficient, and $\sigma$ and $\kappa$ are the electrical and thermal conductivities, respectively. The ideal bulk thermoelectric material has been hypothesized as a "phonon-glass, electron-crystal" (PGEC) material. ${ }^{2}$ Two promising material classes, in particular, have emerged from the PGEC concept, namely, the skutterudites and the clathrates. Both compounds are cage structures capable of encapsulating guest atoms in a host matrix. ${ }^{3,4}$ In the type I clathrates two different cages are present, and the unit cell contains two dodecahedral cages and six larger tetrakaidecahedral cages. The structure belongs to the space group $P m-3 n$ and is shown in Fig. 1(a). Figure 1(b) emphasizes the different host structure sites denoted $6 c, 16 i$, and $24 k$ and shows the subtle difference between the $\mathrm{Ba}_{8} \mathrm{Ga}_{16} \mathrm{Ge}_{30}$ and $\mathrm{Ba}_{8} \mathrm{Ni}_{6} \mathrm{Ge}_{40}$ structures. The host structure represents the electron-crystal part of the PGEC design concept, whereas low energy guest atom phonon modes, also referred to as "rattling" modes, contribute to the phonon-glass properties. The rattling modes interact with heat carrying acoustic phonons and lower the thermal conductivity. Low energy modes have been verified in skutterudites and clathrates by Raman scattering and inelastic neutron scattering (INS). ${ }^{5-9}$ The rattling modes produce an avoided crossing with the acoustic phonons, which reduces

${ }^{a)}$ Electronic mail: bo@chem.au.dk. the group velocity and effectively lowers the thermal conductivity. ${ }^{10}$ Reduction in the rattling energy is expected to lower the thermal conductivity as observed in studies of $X_{8} \mathrm{Ga}_{16} \mathrm{Ge}_{30}(X=\mathrm{Eu}, \mathrm{Sr}$, and $\mathrm{Ba}) .{ }^{11}$ The results suggest that guest atom radii and cage volume play a role for lowering the energy of the rattler modes and the thermal conductivity. $\mathrm{Eu}^{2+}$ has the smallest ionic radius and the lowest thermal conductivity followed by $\mathrm{Sr}^{2+}$, whereas $\mathrm{Ba}^{2+}$ has the largest ionic radius and highest thermal conductivity. ${ }^{12}$ For $n$-type $\mathrm{Eu}_{8} \mathrm{Ga}_{16} \mathrm{Ge}_{30}$ and $n$-type $\mathrm{Sr}_{8} \mathrm{Ga}_{16} \mathrm{Ge}_{30}$ the temperature profile of the thermal conductivity is glasslike, while $n$-type $\mathrm{Ba}_{8} \mathrm{Ga}_{16} \mathrm{Ge}_{30}$ has a "crystalline peak" at low temperature. In contrast to this a glasslike thermal conductivity is observed for $p$-type $\mathrm{Ba}_{8} \mathrm{Ga}_{16} \mathrm{Ge}_{30}{ }^{12}$ Structural investigations of $n$ - and p-type $\mathrm{Ba}_{8} \mathrm{Ga}_{16} \mathrm{Ge}_{30}$ using diffraction and Extended X-ray Absorption Fine Structure (EXAFS) revealed only minor differences between the two compounds. ${ }^{12,13}$ The rattling en-
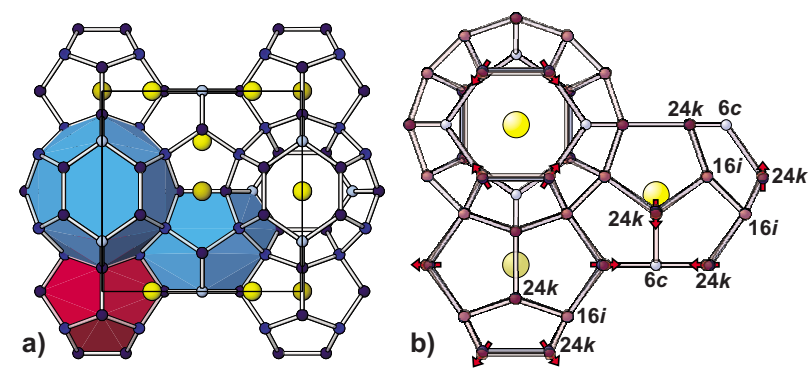

FIG. 1. (Color online) (a) The clathrate type I structure with polygons showing the two different cages. (b) Close-up of the cages with Wyckoff notation of the host structure atoms. The $\mathrm{Ba}_{8} \mathrm{Ni}_{6} \mathrm{Ge}_{30}$ structure has been overlaid on the $\mathrm{Ba}_{8} \mathrm{Ga}_{16} \mathrm{Ge}_{30}$ structure to illustrate the relative displacement of the $24 k$ atom. The arrows indicate the direction of the displacement. 
ergy investigated by powder INS was likewise observed to only differ slightly at room temperature for $n$ - and $p$-type $\mathrm{Ba}_{8} \mathrm{Ga}_{16} \mathrm{Ge}_{30} .{ }^{7}$ The origin of the glasslike thermal conductivity in some clathrates is still discussed in the literature with tunneling states, resonant scattering, anharmonic vibration, and phonon-charge carrier scattering being possible explanations. ${ }^{12-16}$ A recent study of $\mathrm{Sr}_{8} \mathrm{Ga}_{16} \mathrm{Ge}_{x} \mathrm{Si}_{30-x}$ revealed the thermal conductivity to be correlated with the cage volume of the guest atom. ${ }^{17}$ A similar study of $\mathrm{Ba}_{8} \mathrm{Ga}_{16} \mathrm{Ge}_{x} \mathrm{Si}_{30-x}$ on the other hand reveals mass difference scattering to be the major contributor to the reduction in the thermal conductivity at low temperature. ${ }^{18}$ The interplay between low energy phonons, cage volume, and thermal conductivity has motivated the research presented in this paper.

Here we investigate the effect of chemical and physical pressure in type I clathrates by powder INS. The chemical pressure investigations were carried out on barium germanium type I clathrates with the chemical formula $\mathrm{Ba}_{8} Y_{x} \mathrm{Ge}_{46-x} \quad\left(Y_{x}=\mathrm{Ni}_{6}, \mathrm{Cu}_{6}, \mathrm{Zn}_{8}, \mathrm{Ga}_{16}\right)$. Physical pressure data were collected for $\mathrm{Ba}_{8} \mathrm{Ga}_{16} \mathrm{Ge}_{30}$ at ambient pressure and with an applied pressure of 9 kbars using a clamp pressure cell. Furthermore, we have investigated the temperature dependence of the phonon modes with powder INS measurements at 100,200 , and $300 \mathrm{~K}$ for $n$ - and $p$-type $\mathrm{Ba}_{8} \mathrm{Ga}_{16} \mathrm{Ge}_{30}$ and $\mathrm{Sr}_{8} \mathrm{Ga}_{16} \mathrm{Ge}_{30}$. Finally, the chemical pressure samples $\mathrm{Ba}_{8} Y_{x} \mathrm{Ge}_{46-x}\left(Y_{x}=\mathrm{Ni}_{6}, \mathrm{Cu}_{6}, \mathrm{Zn}_{8}\right)$ were used for multitemperature single crystal $\mathrm{x}$-ray diffraction investigations as well as thermoelectric property characterization.

\section{EXPERIMENTAL}

\section{A. Synthesis}

The samples of $\mathrm{Ba}_{8} Y_{x} \mathrm{Ge}_{46-x}\left(Y_{x}=\mathrm{Ni}_{6}, \mathrm{Cu}_{6}\right.$, and $\left.\mathrm{Zn}_{8}\right)$ were prepared using presynthesized $\mathrm{Ba}_{6} \mathrm{Ge}_{25}$, and the necessary amount of the pure elemental $\mathrm{Ni}, \mathrm{Cu}$, or $\mathrm{Zn}$ and $\mathrm{Ge}$ was added to obtain the desired stoichiometry. ${ }^{19}$ The starting materials were sealed in an evacuated carbon coated quartz tube and heated to $1000{ }^{\circ} \mathrm{C}$. The samples were subsequently cooled to $700{ }^{\circ} \mathrm{C}$ and annealed for 5-7 days followed by quenching in air. The samples of $\mathrm{Sr}_{8} \mathrm{Ga}_{16} \mathrm{Ge}_{30}$ and $n$ - and $p$-type $\mathrm{Ba}_{8} \mathrm{Ga}_{16} \mathrm{Ge}_{30}$ are identical to the samples used for measuring the neutron powder INS spectra at room temperature, and the shorthand notation $n$ - and $p$ - $\mathrm{Ba}_{8} \mathrm{Ga}_{16} \mathrm{Ge}_{30}$ will be used. ${ }^{7}$ Another sample batch of $n$-type $\mathrm{Ba}_{8} \mathrm{Ga}_{16} \mathrm{Ge}_{30}$ was prepared for the pressure experiment following the aforementioned method. ${ }^{7}$ This sample will be referred to as $n$ - $\mathrm{Ba}_{8} \mathrm{Ga}_{16} \mathrm{Ge}_{30}$-II.

\section{B. Powder x-ray diffraction}

Powder X-Ray Diffraction (PXRD) data were collected for the samples $\mathrm{Ba}_{8} Y_{x} \mathrm{Ge}_{46-x}\left(Y_{x}=\mathrm{Ni}_{6}, \mathrm{Cu}_{6}, \mathrm{Zn}_{8}\right), \mathrm{Sr}_{8} \mathrm{Ga}_{16}$ $\mathrm{Ge}_{30}$, and $n$ - and $p-\mathrm{Ba}_{8} \mathrm{Ga}_{16} \mathrm{Ge}_{30}$ using a Bruker D8 powder diffractometer. The powder samples were adhered with ethanol to the surface of an oblique cut silicon single crystal. A $\mathrm{LaB}_{6}$ powder standard was added for unit cell calibration. The powder diffraction patterns were subsequently refined using the Rietveld method implemented in FULLPROF. ${ }^{20}$ Since the host structure elements have comparable numbers of electrons, site occupancy factors cannot be refined from the present PXRD data. In $\mathrm{Ba}_{8} \mathrm{Ni}_{6} \mathrm{Ge}_{40}$ and $\mathrm{Ba}_{8} \mathrm{Cu}_{6} \mathrm{Ge}_{40}$ the transition metals were constrained to fully occupy the $6 c$ host structure site. ${ }^{19}$ For $\mathrm{Ba}_{8} \mathrm{Zn}_{8} \mathrm{Ge}_{38}$ and $\mathrm{Ba}_{8} \mathrm{Ga}_{16} \mathrm{Ge}_{30}$ occupancies were fixed to values reported in the literature. ${ }^{12,21}$ The guest atom in the large cage $(\mathrm{Ba} 2)$ was modeled with anisotropic atomic displacement parameters (ADPs) as prescribed by symmetry, while an isotropic parameter was used for the guest atom in the small cage (Ba1) and all host structure atoms. Small Ge impurities were identified in the $\mathrm{Ba}_{8} \mathrm{Cu}_{6} \mathrm{Ge}_{40}, \mathrm{Ba}_{8} \mathrm{Zn}_{8} \mathrm{Ge}_{38}, p-\mathrm{Ba}_{8} \mathrm{Ga}_{16} \mathrm{Ge}_{30}$, and $\mathrm{Sr}_{8} \mathrm{Ga}_{16} \mathrm{Ge}_{30}$ samples, and the refinements gave weight fractions of $3.6(2) \%, 1.6(1) \%, 1.3(1) \%$, and 5.9(1)\%, respectively.

\section{Single crystal x-ray diffraction}

Multitemperature Single Crystal X-Ray Diffraction (SCXRD) data were collected on the chemical pressure samples $\mathrm{Ba}_{8} Y_{x} \mathrm{Ge}_{46-x}\left(Y_{x}=\mathrm{Ni}_{6}, \mathrm{Cu}_{6}, \mathrm{Zn}_{8},\right)$. Full diffraction data sets were collected at 100, 200, 300, and $400 \mathrm{~K}$ using a Bruker APEX-II diffractometer equipped with an Oxford cryostream device for temperature control. The data frames were integrated using SAINT+, and absorption corrections were done with SADABS. The crystallographic refinements were carried out using SHELX. ${ }^{22}$ For $\mathrm{Ba}_{8} \mathrm{Ni}_{6} \mathrm{Ge}_{40}$ and $\mathrm{Ba}_{8} \mathrm{Cu}_{6} \mathrm{Ge}_{40}$ the transition metals were fixed to occupy the $6 c$ site, whereas for $\mathrm{Ba}_{8} \mathrm{Zn}_{8} \mathrm{Ge}_{38}$ the $\mathrm{Zn}$ occupancies were fixed at the values obtained from refinement of neutron diffraction data. $^{21}$ The Ba2 guest atoms were modeled with anisotropic ADPs and positioned in the center of the cage.

\section{Inelastic neutron scattering}

INS spectra were collected using the time-of-flight spectrometer FOCUS at the Paul Scherrer Institute (PSI), Switzerland. $^{23}$ About $10 \mathrm{~g}$ of each sample was sealed in cylindrical aluminum containers. The powder INS spectra were collected with an incident wavelength of $4 \AA$ using neutron energy gain and an optimal energy resolution of $0.25 \mathrm{meV}$ at $-4.5 \mathrm{meV}$. INS spectra were also collected on an empty sample container and a vanadium sample to correct for background and detector efficiency, respectively.

In the physical pressure experiment the sample was loaded in a pressure clamp cell with Fluorinert as a pressure medium and $10 \mathrm{vol} \% \mathrm{NaCl}$ for pressure calibration. The pressure was evaluated from the shift in the unit cell parameters of $\mathrm{NaCl}$ using the two axis spectrometer MORHEUS at PSI, Switzerland. Powder INS spectra were collected at pressures of 9 and 0 kbars. INS data on the empty clamp cell were used for background subtraction.

Temperature dependent measurements were carried out using an Orange ILL-type cryostat. The sample cans were sealed in a He filled glovebox to improve thermal conductivity and remove adsorbed water. The program NATHAN was used for subtracting the background and making the detector efficiency correction. The intensities were subsequently corrected for Bose-Einstein statistics, and the resulting spectra were fitted with 5-7 Gaussian curves. 
TABLE I. Selected results from Rietveld refinements of the x-ray powder diffraction data. The structural parameters are as follows: Ba1, $2 a\left(0,0,0, U_{\text {iso }}\right)$ and $\mathrm{Ba} 2,6 d\left(\frac{1}{4}, \frac{1}{2}, 0, U_{11}, U_{22}=U_{33}\right)$, and for the host structure $6 c\left(\frac{1}{4}, 0, \frac{1}{2}, U_{\text {iso }}\right), 16 i\left(x, x, x, U_{\text {iso }}\right)$, and $24 k\left(0, y, z, U_{\text {iso }}\right)$. For further details see supplementary material. The fractional volume and the volume of the large tetrakaidecahedral cage have been calculated according to procedures explained in the supporting material. The rattler energy $(\hbar \omega)$ from the powder INS data is given at room temperature. The scattering length $(b)$, atomic mass, and atomic radius is listed for $Y$ in $\mathrm{Ba}_{8} Y_{x} \mathrm{Ge}_{46-x}$. The corresponding values for Ge are as follows: $b=8.19 \mathrm{fm}$, mass $=72.64 \mathrm{~g} / \mathrm{mol}$, and atomic radius $=1.22 \AA$.

\begin{tabular}{|c|c|c|c|c|c|c|}
\hline & $\mathrm{Ba}_{8} \mathrm{Ni}_{6} \mathrm{Ge}_{40}$ & $\mathrm{Ba}_{8} \mathrm{Cu}_{6} \mathrm{Ge}_{40}$ & $\mathrm{Ba}_{8} \mathrm{Zn}_{8} \mathrm{Ge}_{38}$ & $n \mathrm{Ba}_{8} \mathrm{Ga}_{16} \mathrm{Ge}_{30}$ & $p \mathrm{Ba}_{8} \mathrm{Ga}_{16} \mathrm{Ge}_{30}$ & $\mathrm{Sr}_{8} \mathrm{Ga}_{16} \mathrm{Ge}_{30}$ \\
\hline Unit cell $(\AA)$ & $10.67488(4)$ & $10.69468(6)$ & $10.76486(6)$ & $10.78258(3)$ & $10.78588(3)$ & $10.72741(3)$ \\
\hline$x(16 i)$ & $0.1825(2)$ & $0.1837(2)$ & $0.1837(3)$ & $0.1835(2)$ & $0.1832(2)$ & $0.1835(2)$ \\
\hline$y(24 k)$ & $0.3175(3)$ & $0.3140(3)$ & $0.3094(5)$ & $0.3079(3)$ & $0.3076(2)$ & $0.3094(3)$ \\
\hline$z(24 k)$ & $0.1216(3)$ & $0.1203(3)$ & $0.1163(4)$ & $0.1181(2)$ & $0.1184(2)$ & $0.1191(2)$ \\
\hline Tetrakaidecahedral volume fraction & 0.1378 & 0.1378 & 0.1386 & 0.1386 & 0.1387 & 0.1384 \\
\hline Tetrakaidecahedral volume $\left(\AA^{3}\right)$ & 167.6 & 168.6 & 172.9 & 173.8 & 174 & 170.8 \\
\hline Dodecahedral volume $\left(\AA^{3}\right)$ & 105.4 & 105.8 & 105.0 & 105.4 & 105.4 & 104.8 \\
\hline$\hbar \omega(\mathrm{meV})$ & $5.42(10)$ & $4.97(1)$ & $4.82(2)$ & $4.52(1)$ & $4.39(2)$ & 4.27(3) \\
\hline$b(\mathrm{fm})$ & 10.3 & 7.7 & 5.7 & 7.3 & 7.3 & 7.3 \\
\hline Mass (g/mol) & 58.69 & 63.55 & 65.39 & 69.72 & 69.72 & 69.72 \\
\hline Atomic radius $(\AA)$ & 1.25 & 1.28 & 1.39 & 1.41 & 1.41 & 1.41 \\
\hline
\end{tabular}

\section{E. Thermoelectric characterization}

The powder samples of $\mathrm{Ba}_{8} Y_{x} \mathrm{Ge}_{46-x} \quad\left(Y_{x}\right.$ $\left.=\mathrm{Ni}_{6}, \mathrm{Cu}_{6}, \mathrm{Zn}_{8}\right)$ were compacted using the spark plasma sintering (SPS) method. The powders were heated at a rate of $\sim 75^{\circ} \mathrm{C} / \mathrm{min}$ and compacted at $100 \mathrm{MPa}$ for $5 \mathrm{~min}$ at 650 , 675 , and $675^{\circ} \mathrm{C}$ for $\mathrm{Ni}, \mathrm{Cu}$, and $\mathrm{Zn}$, respectively. The compacted pellets were cut into parallelepiped samples with dimensions of $\sim 3 \times \sim 3 \times \sim 10 \mathrm{~mm}^{3}$. The thermal transport option in the physical property measurement system from Quantum Design was used for the thermoelectric characterization. The four point quasistatic method was used for simultaneous evaluation of the Seebeck coefficient, resistivity, and thermal conductivity. ${ }^{24}$

\section{RESULTS AND DISCUSSION}

\section{A. Powder x-ray diffraction}

The unit cell and fractional coordinates of the host structure atoms were determined from the Rietveld refinement of the x-ray powder diffraction patterns, and the results are shown in Table I. An estimate of the volume of the large tetrakaidecahedral cage was calculated using the atomic fractional coordinates as vertex points and dividing the polyhedron into infinitesimal layers. The calculation provides the fractional volume of the unit cell occupied by the tetrakaidecahedral cage (referred to as fractional volume). Multiplication of the unit cell volume with the fractional volume gives the volume of the tetrakaidecahedral cage, as tabulated in Table I. The volume of the dodecahedral cage was obtained from the 2:6 ratio of dodecahedral to tetrakaidecahedral cages in the unit cell. The calculation neglects the volume occupied by the atoms forming the cage.

Increasing the atomic radius of the period 4 element causes an increase in unit cell and an expansion of the cage volume. Compared with $\mathrm{Ba}_{8} \mathrm{Ga}_{16} \mathrm{Ge}_{30}$, the host structure atoms located on the $24 k$ site in $\mathrm{Ba}_{8} \mathrm{Ni}_{6} \mathrm{Ge}_{40}$ and $\mathrm{Ba}_{8} \mathrm{Cu}_{6} \mathrm{Ge}_{40}$ move toward the $6 c$ site, which is occupied by the transition metal, as illustrated in Fig. 1(b). The fractional volume of the tetrakaidecahedral cage is observed to be similar for $\mathrm{Ba}_{8} \mathrm{Ga}_{16} \mathrm{Ge}_{30}$ and $\mathrm{Ba}_{8} \mathrm{Zn}_{8} \mathrm{Ge}_{38}$, whereas $\mathrm{Ba}_{8} \mathrm{Cu}_{6} \mathrm{Ge}_{40}$ and
$\mathrm{Ba}_{8} \mathrm{Ni}_{6} \mathrm{Ge}_{40}$ have smaller but again comparable fractional volumes. These smaller fractional volumes can be explained by the shift of the fractional coordinates of the atom on the $24 k$ site, see Table I.

The volume of the small dodecahedral cage $\left(\sim 105 \AA^{3}\right)$ is observed to be almost identical for all investigated compounds. This is explainable as the transition metal preferentially occupies the $6 c$ site, which does not occur in the dodecahedral cage. The dodecahedral cage is predominately build of $\mathrm{Ge}^{25}$

\section{B. Single crystal x-ray diffraction}

A summary of the key parameters obtained from refinement of the $300 \mathrm{~K}$ single crystal diffraction data is shown in Table II. A detailed description of the refinements is given in supplementary material. ${ }^{26}$ Comparison of extracted unit cell parameters from single crystal (Table II) and powder diffraction (Table I) reveals a considerable difference. Typically, unit cell parameters for simple structures are determined better by PXRD than by SCXRD. However, the fractional coordinates obtained from PXRD and SCXRD agree well, and this confirms the movement of host structure atoms at the $24 k$ site toward the atoms at the $6 c$ site. This is supported by the bond distance given in Table II, which reveals contraction of the $6 c-24 k$ bond when going toward smaller host structure atoms. The bond between $16 i-24 k$ is kept almost constant, whereas the $24 k-24 k$ bond expands.

Multitemperature ADPs can be modeled with an Einstein model in the case of the guest atoms and a Debye model for the host structure atoms. ${ }^{25}$ For the guest atoms such modeling provides an estimate of the rattling energy in the form of the Einstein temperature, whereas the Debye temperature obtained for the host framework, e.g., can be used to estimate the mean velocity of sound. In the Einstein model the ADPs in the direction $x x$ are given as

$$
U_{x x}(T)=\frac{\hbar^{2}}{2 m k_{B} \theta_{E, x x}} \operatorname{coth}\left(\frac{\theta_{E, x x}}{2 T}\right)+d^{2},
$$

where $m$ is the guest atom mass, $\theta_{E, x x}$ is the Einstein temperature, and $d^{2}$ is a temperature independent disorder term. 
TABLE II. Selected results from refinements of the $300 \mathrm{~K}$ single crystal $\mathrm{x}$-ray diffraction data. The guest atoms are refined with the following structural parameters: $\mathrm{Ba} 1,2 a\left(0,0,0, U_{\text {iso }}\right)$ and $\mathrm{Ba} 2,6 d\left(\frac{1}{4}, \frac{1}{2}, 0, U_{11}, U_{22}=U_{33}\right)$, and host structure atoms with $6 c\left(\frac{1}{4}, 0, \frac{1}{2}, U_{11}, U_{22}=U_{33}\right), 16 i\left(x, x, x, U_{11}\right.$ $\left.=U_{22}=U_{33}, U_{12}=U_{13}=U_{23}\right)$, and $24 k\left(0, y, z, U_{11}, U_{22}, U_{33}, U_{23}\right)$. Details from the refinement of data at other temperatures are given in supplementary materials.

\begin{tabular}{lccc}
\hline \hline & $\mathrm{Ba}_{8} \mathrm{Ni}_{6} \mathrm{Ge}_{40}$ & $\mathrm{Ba}_{8} \mathrm{Cu}_{6} \mathrm{Ge}_{40}$ & $\mathrm{Ba}_{8} \mathrm{Zn}_{8} \mathrm{Ge}_{38}$ \\
\hline$T(\mathrm{~K})$ & 300 & 300 & 300 \\
$a(\AA)$ & $10.6891(2)$ & $10.7492(5)$ & $10.7534(1)$ \\
$U_{\text {iso }}(\mathrm{Ba} 1)\left(\times 10^{-4} \AA^{2}\right)$ & $133(1)$ & $113(2)$ & $112(1)$ \\
$U_{11}(\mathrm{Ba} 2)\left(\times 10^{-4} \AA^{2}\right)$ & $221(3)$ & $237(4)$ & $191(3)$ \\
$U_{22}(\mathrm{Ba} 2)\left(\times 10^{-4} \AA^{2}\right)$ & $531(3)$ & $414(4)$ & $441(3)$ \\
$x(16 i)$ & $0.18362(3)$ & $0.18311(4)$ & $0.18367(3)$ \\
$y(24 k)$ & $0.31671(4)$ & $0.31477(5)$ & $0.30971(4)$ \\
$z(24 k)$ & $0.12200(5)$ & $0.11975(5)$ & $0.11762(4)$ \\
$U_{\text {iso }}($ host $)\left(\times 10^{-4} \AA^{2}\right)$ & $140(1)$ & $107(2)$ & $115(1)$ \\
& & & \\
$\mathrm{N}_{\text {par }}$ & 16 & 16 & 16 \\
$N, N\left[F_{\text {obs }}>4 \sigma\left(F_{\text {obs }}\right)\right]$ & 1084,718 & 959,585 & 1147,796 \\
$R_{F}, R_{F}\left[F_{\text {obs }}>4 \sigma\left(F_{\text {obs }}\right)\right]$ & $6.2 \%, 3.4 \%$ & $8.1 \%, 3.3 \%$ & $5.8 \%, 3.4 \%$ \\
GoF, $R_{w I}(\mathrm{~N})$ & $0.69,11.4 \%$ & $0.78,13.4 \%$ & $0.81,12.4 \%$ \\
& & & \\
Bond distances & & & \\
$6 c-24 k$ & $2.390(1)$ & $2.434(1)$ & $2.493(1)$ \\
$16 i-16 i$ & $2.458(1)$ & $2.491(1)$ & $2.471(1)$ \\
$16 i-24 k$ & $2.512(1)$ & $2.518(1)$ & $2.499(1)$ \\
$24 k-24 k$ & $2.608(1)$ & $2.574(1)$ & $2.530(1)$ \\
\hline \hline
\end{tabular}

Care has to be taken when interpreting the disorder term as systematic errors in diffraction data will affect this value. On the other hand the Einstein temperatures are relatively unaffected by systematic errors. The Debye expression for the occupancy weighted APDs of the host structure atoms is

$$
U_{\text {iso }}(T)=\frac{3 \hbar^{2} T}{m k_{B} \theta_{D}^{2}}\left[\frac{T}{\theta_{D}} \int_{0}^{\theta_{D} / T} \frac{x}{\exp (x)-1} d x+\frac{\theta_{D}}{4 T}\right]+d^{2},
$$

where $m$ is the stoichiometry weighted average mass of the host structure atoms, $\theta_{D}$ is the Debye temperature, and $d^{2}$ is the disorder term. Figure 2 shows the ADPs and corresponding Einstein and Debye model fits for $\mathrm{Ba}_{8} Y_{x} \mathrm{Ge}_{46-x}\left(Y_{x}\right.$ $\left.=\mathrm{Ni}_{6}, \mathrm{Cu}_{6}, \mathrm{Zn}_{8}\right)$. The corresponding model parameters are listed in Table III along with various literature values. The barium guest atom in the small dodecahedral cage $\theta_{E \text {,iso }}(\mathrm{Ba} 1)$ behaves similarly for all four compounds. This was expected as the volume of the dodecahedral cage was identical for the investigated samples. The Einstein temperature associated with movement perpendicular to the six member ring in the large tetrakaidecahedral cage, $\theta_{E, 11}(\mathrm{Ba} 2)$, is also similar for all samples. However, the Einstein temperature in the equatorial plane, $\theta_{E, 22}(\mathrm{Ba} 2)$, is significantly larger for $\mathrm{Ba}_{8} \mathrm{Ni}_{6} \mathrm{Ge}_{40}$ than in the other three compounds. The Einstein temperatures for $\mathrm{Ba}_{8} \mathrm{Ni}_{6} \mathrm{Ge}_{40}$ and $\mathrm{Ba}_{8} \mathrm{Cu}_{6} \mathrm{Ge}_{40}$ are in good agreement with earlier results obtained from multitemperature powder diffraction (see Table III). ${ }^{19,27}$ Likewise the result for $\mathrm{Ba}_{8} \mathrm{Zn}_{8} \mathrm{Ge}_{38}$ is in fair agreement with results obtained from single crystal $\mathrm{x}$-ray and neutron diffraction. ${ }^{21,28}$ The disorder parameter for the guest atom vibrating in the equatorial plan has significantly higher values for $\mathrm{Ba}_{8} \mathrm{Ni}_{6} \mathrm{Ge}_{40}$ than for the other samples. The Debye temperatures are comparable for all compounds as expected from the structural similarity and similar host atom masses.

\section{Inelastic neutron scattering}

Bose-Einstein corrected powder INS spectra for the period 4 element series are shown in Fig. 3. A generalized phonon density of states can be obtained by multiplying the intensity by energy. The true phonon density of states, however, is difficult to calculate since it depends on multiphonon scattering, atomic site occupancy factors, atomic scattering lengths, and atomic masses. Nevertheless, the energy corrected phonon density of states must be fairly close to the true phonon density of states due to the similarities of masses and scattering lengths of the host structure atoms. The structural resemblance, similar scattering lengths, and masses of $\mathrm{Ba}_{8} Y_{x} \mathrm{Ge}_{46-x}\left(Y_{x}=\mathrm{Ni}_{6}, \mathrm{Cu}_{6}, \mathrm{Zn}_{8}\right.$, and $\left.\mathrm{Ga}_{16}\right)$ are reflected in the virtually identical powder INS spectra in Fig. 3. Gaussian functions have been used to fit the observed peaks, and the resulting energy values are listed in the supplementary material.

Generally, all data can be described by a low and a high energy region. The low energy region is characterized by a distinct peak with a weaker shoulder at higher energy, except for $\mathrm{Ba}_{8} \mathrm{Ni}_{6} \mathrm{Ge}_{40}$, where the features appear to be broadened and the shoulder is indistinguishable. The high energy region

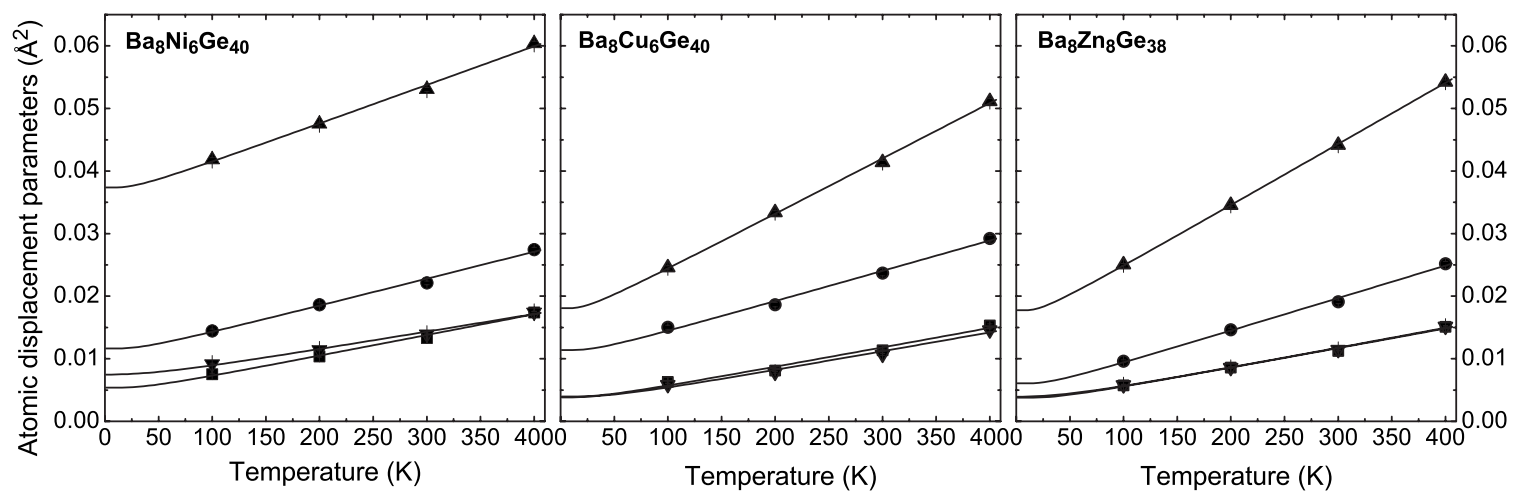

FIG. 2. The ADPs as a function of temperature for $\mathrm{Ba}_{8} \mathrm{Ni}_{6} \mathrm{Ge}_{40}, \mathrm{Ba}_{8} \mathrm{Cu}_{6} \mathrm{Ge}_{40}$, and $\mathrm{Ba}_{8} \mathrm{Zn}_{8} \mathrm{Ge}_{38}$ (left to right). Triangles pointing up are $U_{22}$ (Ba2), circles are $U_{11}(\mathrm{Ba} 2)$, squares are $U_{\text {iso }}(\mathrm{Ba} 1)$, and inverted triangles are averaged host structure $U_{\text {iso. }}$. The lines represent the Einstein and Debye fits. 
TABLE III. Einstein $\left(\theta_{E}\right)$ and Debye $\left(\theta_{D}\right)$ temperatures and the disorder parameter $(d)$ obtained from multitemperature single crystal $\mathrm{x}$-ray diffraction data. Literature values are listed for comparison.

\begin{tabular}{|c|c|c|c|c|c|c|c|c|}
\hline \multirow[b]{2}{*}{ Compound } & \multicolumn{2}{|c|}{$U_{\text {iso }}(\mathrm{Ba} 1)$} & \multicolumn{2}{|c|}{$U_{11}(\mathrm{Ba} 2)$} & \multicolumn{2}{|c|}{$U_{22}(\mathrm{Ba} 2)$} & \multicolumn{2}{|c|}{$U_{\text {iso }}($ host $)$} \\
\hline & $\begin{array}{c}\theta_{E} \\
(\mathrm{~K})\end{array}$ & $\begin{array}{c}d \\
(\AA)\end{array}$ & $\begin{array}{c}\theta_{E} \\
(\mathrm{~K})\end{array}$ & $\begin{array}{c}d \\
(\AA)\end{array}$ & $\begin{array}{c}\theta_{E} \\
(\mathrm{~K})\end{array}$ & $\begin{array}{c}d \\
(\AA)\end{array}$ & $\begin{array}{c}\theta_{D} \\
(\mathrm{~K})\end{array}$ & $\begin{array}{c}d \\
(\AA)\end{array}$ \\
\hline $\mathrm{Ba}_{8} \mathrm{Ni}_{6} \mathrm{Ge}_{40}$ & $103(3)$ & $0.061(4)$ & $85(2)$ & $0.098(3)$ & $75.4(1.7)$ & $0.187(2)$ & $268(8)$ & $0.075(3)$ \\
\hline $\mathrm{Ba}_{8} \mathrm{Cu}_{6} \mathrm{Ge}_{40}$ & $106(5)$ & $0.048(9)$ & $82(2)$ & $0.097(4)$ & $63.1(8)$ & $0.124(3)$ & $258(11)$ & $0.043(9)$ \\
\hline $\mathrm{Ba}_{8} \mathrm{Zn}_{8} \mathrm{Ge}_{38}$ & $105(3)$ & $0.045(6)$ & $84(1)$ & $0.062(6)$ & $60.0(3)$ & $0.122(1)$ & $251(5)$ & $0.044(4)$ \\
\hline$n-\mathrm{Ba}_{8} \mathrm{Ga}_{16} \mathrm{Ge}_{30}{ }^{\mathrm{a}}$ & $108(1)$ & $0.023(2)$ & $87(2)$ & $0.021(9)$ & $59.7(5)$ & $0.127(2)$ & $274(3)$ & $0.012(7)$ \\
\hline $\mathrm{Ba}_{8} \mathrm{Ni}_{6} \mathrm{Ge}_{40} \mathrm{~b}$ & $109(1)$ & 0.0263 & $95(1)$ & $0.075(1)$ & $78.8(1.1)$ & $0.170(1)$ & & \\
\hline $\mathrm{Ba}_{8} \mathrm{Cu}_{6} \mathrm{Ge}_{40}{ }^{\mathrm{c}}$ & & & $92(2)$ & $0.080(2)$ & $64.3(4)$ & $0.109(1)$ & & \\
\hline $\mathrm{Ba}_{8} \mathrm{Zn}_{8} \mathrm{Ge}_{38}^{\mathrm{d}}$ & 118 & 0.047 & 98 & 0.063 & 62 & 0.177 & 279 & 0.043 \\
\hline $\mathrm{Ba}_{8} \mathrm{Zn}_{8} \mathrm{Ge}_{38}{ }^{\mathrm{e}}$ & & & 85 & & 64 & & & \\
\hline
\end{tabular}

${ }^{\mathrm{a}}$ Reference 13.
${ }^{\mathrm{b}}$ Reference 19.
${ }^{\mathrm{c}}$ Reference 27.
${ }^{\mathrm{d}}$ Reference 21.
${ }^{\mathrm{e}}$ Reference 28.

$(\hbar \omega>7 \mathrm{meV})$ is characterized by a number of overlapping peaks. The density of modes appears to end abruptly around 14-15 meV. Additional modes are observed at higher energies $(\hbar \omega>25 \mathrm{meV})$, but these modes will not be considered here. The first two peaks in the low energy region have been tentatively assigned to the equatorial $\left(\mathrm{Ba}_{2}\right.$ equ $)$ and perpendicular $\left(\mathrm{Ba}_{2}\right.$ per $)$ modes of the $\mathrm{Ba} 2$ guest atom in the large tetrakaidecahedral cage. ${ }^{7}$ The energy of the first mode decreases as the atomic radius of the host structure atom increases. $\mathrm{Ba}_{8} \mathrm{Ga}_{16} \mathrm{Ge}_{30}$ and $\mathrm{Ba}_{8} \mathrm{Zn}_{8} \mathrm{Ge}_{38}$ have similar energies for the phonon modes above $6 \mathrm{meV}$. This is also the case for $\mathrm{Ba}_{8} \mathrm{Cu}_{6} \mathrm{Ge}_{40}$ and $\mathrm{Ba}_{8} \mathrm{Ni}_{6} \mathrm{Ge}_{40}$, but in these samples the modes are shifted to higher energy, suggesting a stiffer framework compared with $\mathrm{Ba}_{8} \mathrm{Ga}_{16} \mathrm{Ge}_{30}$ and $\mathrm{Ba}_{8} \mathrm{Zn}_{8} \mathrm{Ge}_{38}$. This could be an effect of the relative $24 k$ atom displacement in $\mathrm{Ba}_{8} \mathrm{Ni}_{6} \mathrm{Ge}_{40}$ and $\mathrm{Ba}_{8} \mathrm{Cu}_{6} \mathrm{Ge}_{40}$.

In Fig. 4 the energy of the $\mathrm{Ba}_{2}$ equ mode is plotted against the tetrakaidecahedral cage volume. As the cage volume expands from $\mathrm{Ba}_{8} \mathrm{Ni}_{6} \mathrm{Ge}_{40}$ to $\mathrm{Ba}_{8} \mathrm{Cu}_{6} \mathrm{Ge}_{40}$ the energy decreases by $-0.47 \mathrm{meV} / \AA^{3}$. Between $\mathrm{Ba}_{8} \mathrm{Cu}_{6} \mathrm{Ge}_{40}$ and $\mathrm{Ba}_{8} \mathrm{Zn}_{8} \mathrm{Ge}_{38}$ the volume increase has little effect on the energy. A further increase in cage volume from $\mathrm{Ba}_{8} \mathrm{Zn}_{8} \mathrm{Ge}_{38}$ to the two $\mathrm{Ba}_{8} \mathrm{Ga}_{16} \mathrm{Ge}_{30}$ samples results in a significant drop in rattler energy $\left(-0.38 \mathrm{meV} / \AA^{3}\right)$.

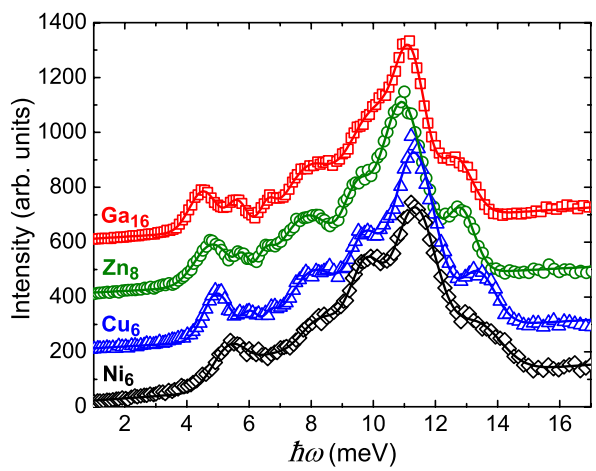

FIG. 3. (Color online) Powder INS spectra for $\mathrm{Ba}_{8} Y_{x} \mathrm{Ge}_{46}\left(Y_{x}\right.$ $=\mathrm{Ni}_{6}, \mathrm{Cu}_{6}, \mathrm{Zn}_{8}, \mathrm{Ga}_{16}$ ) with $\mathrm{Ni}_{6}$ (diamonds), $\mathrm{Cu}_{6}$ (triangles), $\mathrm{Zn}_{8}$ (circles), and $\mathrm{Ga}_{16}$ (squares). The spectra have been successively offset by 200 counts for clarity.
The clamp cell powder INS spectra collected at ambient pressure and at 9 kbars for $n-\mathrm{Ba}_{8} \mathrm{Ga}_{16} \mathrm{Ge}_{30}$-II are shown in Fig. 5, along with data for the $n-\mathrm{Ba}_{8} \mathrm{Ga}_{16} \mathrm{Ge}_{30}$-II sample in a conventional aluminum sample holder. The clamp cell broadens the features of the spectrum. The applied pressure causes the rattling modes to shift toward higher energies. The three lowest energy modes show the largest change due to the applied pressure, whereas the modes above $7 \mathrm{meV}$ are less influenced by pressure. The results reveal that the phonon mode of the $\mathrm{Ba} 2_{\text {equ }}$ guest atom is dependent on the volume of the cage. Diffraction peak shifts at 9 kbars were used to establish the unit cell shrinkage, which is $0.2 \%$ relative to ambient pressure. As only few Bragg reflections were measured at high pressure it was not possible to refine the crystal structure. It is therefore assumed that the fractional coordinates are unchanged and correspondingly that the fractional volume of the large cage can be scaled by the reduction in the unit cell volume. Solid squares in Fig. 4 represent the energy of the $\mathrm{Ba} 2$ atom as a function of cage volume in the pressure experiment. At ambient pressure the clamp cell and the conventional sample holder give identical energies within uncertainties for the rattler mode. Moreover, the energies of

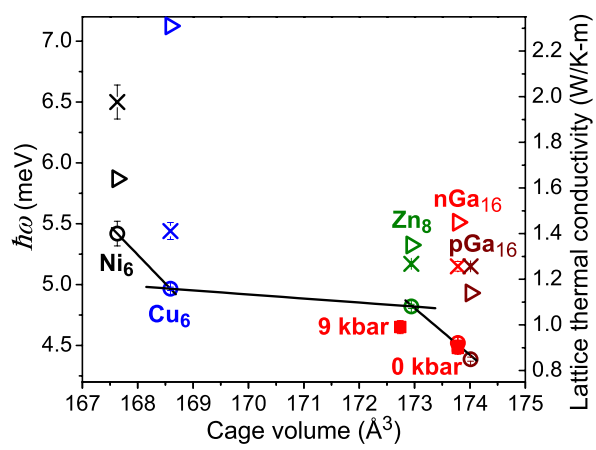

FIG. 4. (Color online) The effect of the cage volume on rattler energy and lattice thermal conductivity. The volume goes from smallest to largest for $\mathrm{Ni}_{6}, \mathrm{Cu}_{6}, \mathrm{Zn}_{8}, n \mathrm{Ga}_{16}$, and $p \mathrm{Ga}_{16}$. Open circles are rattler energies extracted from the powder INS spectra, whereas Einstein temperatures extracted from $\mathrm{x}$-ray data are shown as x's. The lines are guides to the eyes. The solid squares are the results from the INS pressure experiment. Triangles are to lattice thermal conductivities at $250 \mathrm{~K}$. 


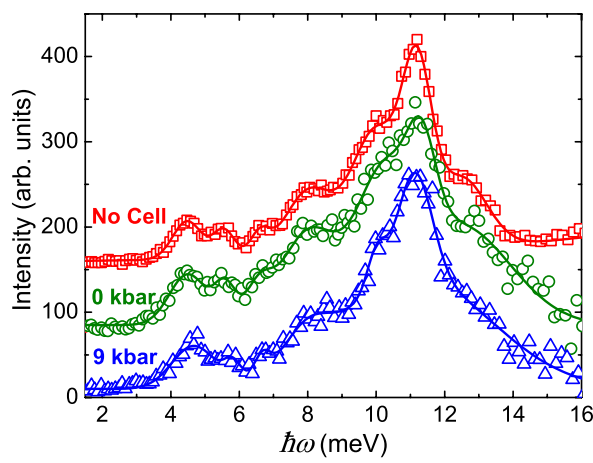

FIG. 5. (Color online) INS spectra of $n$ - $\mathrm{Ba}_{8} \mathrm{Ga}_{16} \mathrm{Ge}_{30}$-II. Squares indicate data collected at ambient pressure with an aluminum sample holder, circles are for data collected at ambient pressure with the sample loaded into the pressure cell, and triangles are for the $n-\mathrm{Ba}_{8} \mathrm{Ga}_{16} \mathrm{Ge}_{30}$-II sample under an applied pressure of 9 kbars. The spectra have been offset for clarity.

$n$ - $\mathrm{Ba}_{8} \mathrm{Ga}_{16} \mathrm{Ge}_{30}$-II and $n-\mathrm{Ba}_{8} \mathrm{Ga}_{16} \mathrm{Ge}_{30}$ are equivalent, which gives confidence in the reproducibility of the synthesis and the data collection. The small variations observed between $n$ and $p-\mathrm{Ba}_{8} \mathrm{Ga}_{16} \mathrm{Ge}_{30}$ are genuine. ${ }^{7}$ The applied pressure produces a smaller energy shift than observed by the chemical pressure when going from $n-\mathrm{Ba}_{8} \mathrm{Ga}_{8} \mathrm{Ge}_{30}$ to $\mathrm{Ba}_{8} \mathrm{Zn}_{8} \mathrm{Ge}_{38}$. Thus, space availability is not the only factor affecting the rattler energy, and the chemical environment surrounding the guest atom also appears to play an important role.

The clathrate type $\mathrm{I} \mathrm{Ba}_{8} \mathrm{Si}_{46-x} \square_{x}$ system ( $\square=$ vacancy) has been intensively studied because of its superconducting properties. ${ }^{29,30}$ A high pressure Raman spectroscopy study of $\mathrm{Ba}_{8} \mathrm{Si}_{46}$ revealed an energy increase for all modes, ${ }^{31}$ whereas in the present INS experiment on $n$ - $\mathrm{Ba}_{8} \mathrm{Ga}_{16} \mathrm{Ge}_{30}$-II only the guest atom modes are affected. However, the pressures applied in the $\mathrm{Ba}_{8} \mathrm{Si}_{46}$ study were much higher $(\sim 1.7-20$ $\mathrm{GPa})$ than used here for $\mathrm{Ba}_{8} \mathrm{Ga}_{16} \mathrm{Ge}_{30}(0.9 \mathrm{GPa})$. In a recent study of $\mathrm{Ba}_{8} \mathrm{Ge}_{43} \square_{3}$ it was likewise observed that all modes shift to higher energies with applied pressure, ${ }^{32}$ but again the applied pressures were higher (2.6-22 GPa) compared with the pressure used in this study.

Temperature dependent powder INS spectra were collected for $\mathrm{Sr}_{8} \mathrm{Ga}_{16} \mathrm{Ge}_{30}$ and $n$ - and $p-\mathrm{Ba}_{8} \mathrm{Ga}_{16} \mathrm{Ge}_{30}$ at 100 , 200, and 300 K. Figure 6 shows the INS spectra for $\mathrm{Sr}_{8} \mathrm{Ga}_{16} \mathrm{Ge}_{30}$ and $p$ - $\mathrm{Ba}_{8} \mathrm{Ga}_{16} \mathrm{Ge}_{30}$. The room temperature data for all the samples and multitemperature data for $n$ - $\mathrm{Ba}_{8} \mathrm{Ga}_{16} \mathrm{Ge}_{30}$ have previously been reported by Christensen et al. ${ }^{7,10}$ The powder INS spectra in Fig. 6 reveal a softening of the energy mode related to the guest atom with decreasing temperature. The effects of temperature on the higher energy modes are less obvious, although the most intense mode around $10.5 \mathrm{meV}$ for $\mathrm{Sr}_{8} \mathrm{Ga}_{16} \mathrm{Ge}_{30}$ and $11 \mathrm{meV}$ for $p$ - $\mathrm{Ba}_{8} \mathrm{Ga}_{16} \mathrm{Ge}_{30}$ increases in energy with decreasing temperature. The softening of the first two guest atom modes with decreasing temperature is shown in Fig. 7, and it points to an anharmonic potential for the guest atom in the large cage. The results from $n-\mathrm{Ba}_{8} \mathrm{Ga}_{16} \mathrm{Ge}_{30}$ have been included for completeness. The $p$ - $\mathrm{Ba}_{8} \mathrm{Ga}_{16} \mathrm{Ge}_{30}$ sample has lower energy modes than $n$ - $\mathrm{Ba}_{8} \mathrm{Ga}_{16} \mathrm{Ge}_{30}$, but the temperature dependence of the energies is comparable for the two systems. This suggests that the shape of the anharmonic potential is similar for $n-\mathrm{Ba}_{8} \mathrm{Ga}_{16} \mathrm{Ge}_{30}$ and $p-\mathrm{Ba}_{8} \mathrm{Ga}_{16} \mathrm{Ge}_{30}$. The mode associated

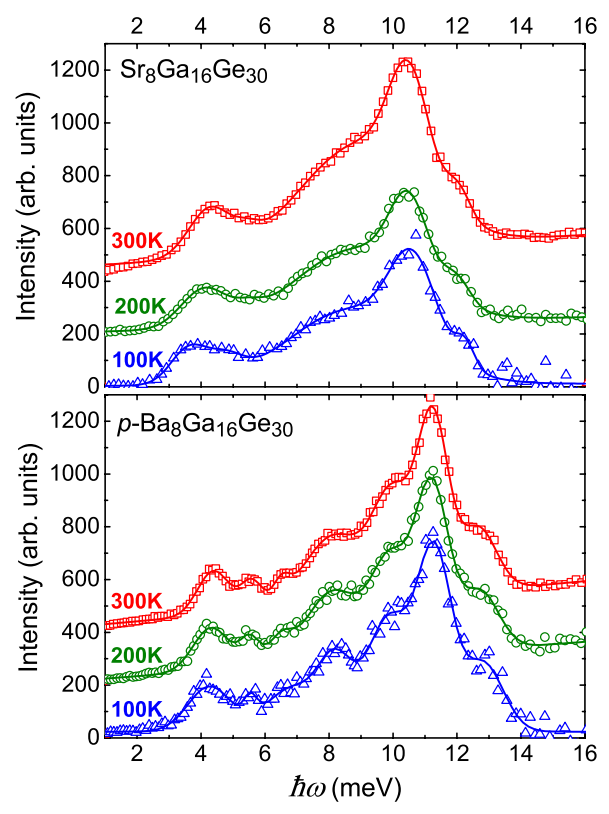

FIG. 6. (Color online) INS spectra collected as a function of temperature for $\mathrm{Sr}_{8} \mathrm{Ga}_{16} \mathrm{Ge}_{30}$ and $p-\mathrm{Ba}_{8} \mathrm{Ga}_{16} \mathrm{Ge}_{30}$. The temperatures of 300,200 , and $100 \mathrm{~K}$ are shown with squares, circles, and triangles, respectively. The spectra have been offset for clarity.

with the $\mathrm{Sr} 2$ guest atom in $\mathrm{Sr}_{8} \mathrm{Ga}_{16} \mathrm{Ge}_{30}$ on the other hand has a significantly stronger temperature dependence than $\mathrm{Ba} 2$ in the $\mathrm{Ba}_{8} \mathrm{Ga}_{16} \mathrm{Ge}_{30}$ samples, which shows that the $\mathrm{Sr} 2$ guest atom sits in a stronger anharmonic potential. The rattler energy for $n-\mathrm{Ba}_{8} \mathrm{Ga}_{16} \mathrm{Ge}_{30}$ at $100 \mathrm{~K}[\hbar \omega=4.35(4) \mathrm{meV}]$ is comparable to the $300 \mathrm{~K}$ value for $p$ - $\mathrm{Ba}_{8} \mathrm{Ga}_{16} \mathrm{Ge}_{30}[\hbar \omega$ $=4.39(2) \mathrm{meV}]$. This is interesting because the differenceFourier nuclear densities observed for $n-\mathrm{Ba}_{8} \mathrm{Ga}_{16} \mathrm{Ge}_{30}$ at 100 $\mathrm{K}$ and $p$ - $\mathrm{Ba}_{8} \mathrm{Ga}_{16} \mathrm{Ge}_{30}$ at $300 \mathrm{~K}$ indeed are similar. ${ }^{13}$ This confirms that the potentials are similar in shape in $n$ - and $p$ - $\mathrm{Ba}_{8} \mathrm{Ga}_{16} \mathrm{Ge}_{30}$, but that the levels are offset in energy. The multitemperature powder INS spectra on $\mathrm{Ba}_{8} \mathrm{Ga}_{16} \mathrm{Ge}_{30}$ do not explain why the $p$-type sample has a glasslike thermal conductivity, whereas the $n$-type sample has a normal crystalline thermal conductivity as a function of temperature. ${ }^{12}$ The shapes of the anharmonic potentials appear to be similar, so it is unlikely that it is the guest atom as such, which is the origin of the differences in thermal conductivity.

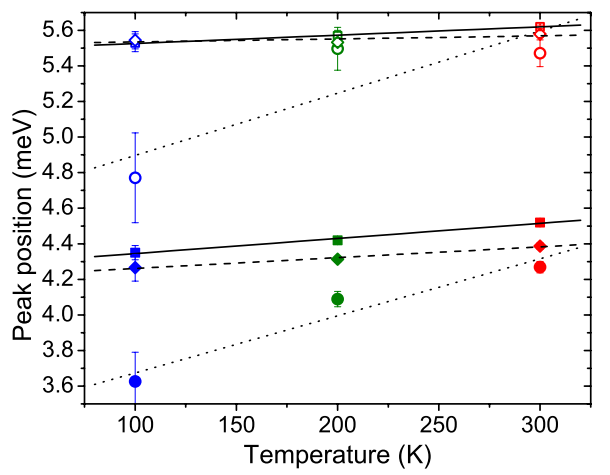

FIG. 7. (Color online) The energy of the first (solid) and second (open) peaks observed by INS as function of temperature. $\mathrm{Sr}_{8} \mathrm{Ga}_{16} \mathrm{Ge}_{30}$ and $n$ - and $p$ - $\mathrm{Ba}_{8} \mathrm{Ga}_{16} \mathrm{Ge}_{30}$ are shown as circles, squares, and diamonds, respectively, and the corresponding fits are shown as dotted, solid, and dashed lines. 


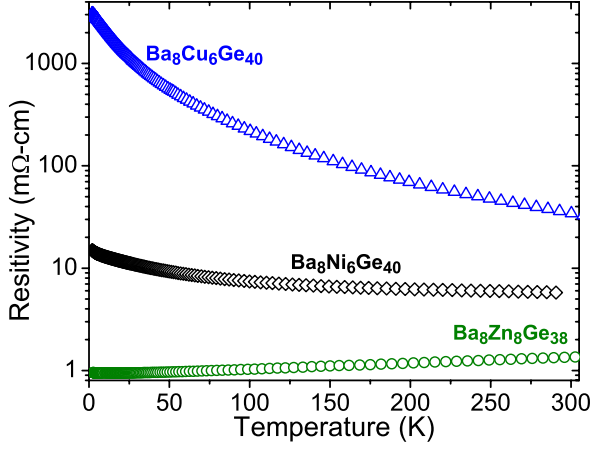

FIG. 8. (Color online) Electrical resistivity as a function of temperature for $\mathrm{Ba}_{8} \mathrm{Ni}_{6} \mathrm{Ge}_{30}$ (diamonds), $\mathrm{Ba}_{8} \mathrm{Cu}_{6} \mathrm{Ge}_{30}$ (triangles), and $\mathrm{Ba}_{8} \mathrm{Zn}_{8} \mathrm{Ge}_{38}$ (circles).

Temperature dependent Raman spectroscopy data of $\mathrm{Ba}_{8} \mathrm{Ga}_{16} \mathrm{Ge}_{30}$ and $\mathrm{Sr}_{8} \mathrm{Ga}_{16} \mathrm{Ge}_{30}$ also show a decrease in the energy of the guest atom mode with decreasing temperature. ${ }^{8}$ The room temperature values of the Raman spectroscopy energies of the first rattler mode are 3.91 and $4.28 \mathrm{meV}$ for $\mathrm{Sr}_{8} \mathrm{Ga}_{16} \mathrm{Ge}_{30}$ and $\mathrm{Ba}_{8} \mathrm{Ga}_{16} \mathrm{Ge}_{30}$, respectively. The lower Raman energies are explained by the dispersive behavior of the guest atom mode, as was shown by Christensen et al. ${ }^{10}$

\section{Transport properties}

The electrical resistivities of $\mathrm{Ba}_{8} Y_{x} \mathrm{Ge}_{46-x} \quad\left(Y_{x}\right.$ $\left.=\mathrm{Ni}_{6}, \mathrm{Cu}_{6}, \mathrm{Zn}_{8}\right)$ are shown in Fig. 8. The decreasing resistivity of $\mathrm{Ba}_{8} \mathrm{Ni}_{6} \mathrm{Ge}_{40}$ and $\mathrm{Ba}_{8} \mathrm{Cu}_{6} \mathrm{Ge}_{40}$ as function of temperature reveals them to be semiconductors, whereas $\mathrm{Ba}_{8} \mathrm{Zn}_{8} \mathrm{Ge}_{38}$ show a (poor) metallic behavior. Samples with ideal stoichiometry are expected to have a high resistivity according to the Zintl concept. Consequently the present samples presumably are close to being Zintl phases. Figure 9 shows the temperature profile of the Seebeck coefficient. Negative Seebeck coefficients point to electrons as dominant charge carriers for all three samples. $\mathrm{Ba}_{8} \mathrm{Zn}_{8} \mathrm{Ge}_{38}$ decreases monotonically within the measured temperature range. Similar to the study by Melnychenko-Koblyuk et l. $^{28}$ a wiggle is observed in the Seebeck coefficient below $100 \mathrm{~K}$ for $\mathrm{Ba}_{8} \mathrm{Cu}_{6} \mathrm{Ge}_{40}$. Among the studied samples, $\mathrm{Ba}_{8} \mathrm{Cu}_{6} \mathrm{Ge}_{40}$ goes from having the smallest absolute Seebeck coefficient at $50 \mathrm{~K}$ to having the highest at about $250 \mathrm{~K}$. This behavior may be explained

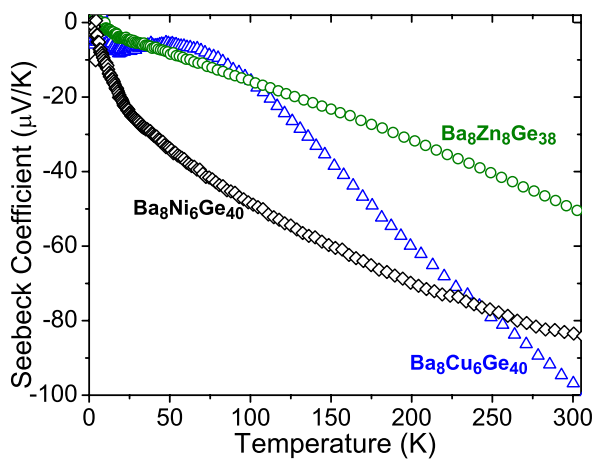

FIG. 9. (Color online) Seebeck coefficient as a function of temperature for $\mathrm{Ba}_{8} \mathrm{Ni}_{6} \mathrm{Ge}_{30}$ (diamonds), $\mathrm{Ba}_{8} \mathrm{Cu}_{6} \mathrm{Ge}_{30}$ (triangles), and $\mathrm{Ba}_{8} \mathrm{Zn}_{8} \mathrm{Ge}_{38}$ (circles).

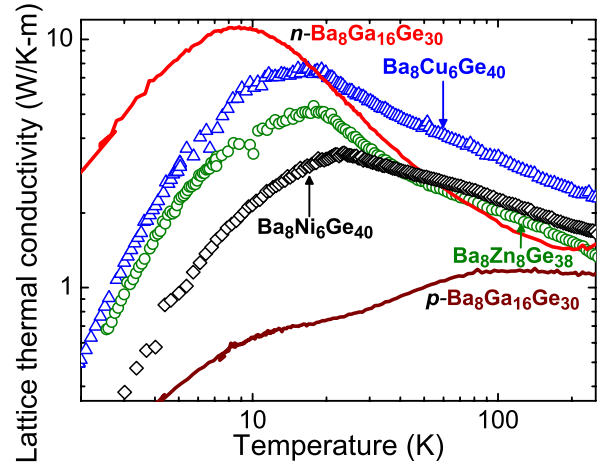

FIG. 10. (Color online) Lattice thermal conductivity as a function of temperature for $\mathrm{Ba}_{8} \mathrm{Ni}_{6} \mathrm{Ge}_{30}$ (diamonds), $\mathrm{Ba}_{8} \mathrm{Cu}_{6} \mathrm{Ge}_{30}$ (triangles), and $\mathrm{Ba}_{8} \mathrm{Zn}_{8} \mathrm{Ge}_{38}$ (circles). The charge carrier contribution has been subtracted from the observed thermal conductivity using Wiedemann-Franz law. For comparison the thermal conductivity for $n$ - and $p-\mathrm{Ba}_{8} \mathrm{Ga}_{16} \mathrm{Ge}_{30}$ is included (Ref. 31).

by the sample having both holes and electrons as charge carriers at low temperatures, whereas electrons dominate at high temperatures $(T>100 \mathrm{~K})$.

The lattice thermal conductivities are shown in Fig. 10, where data for $n$ - and $p$ - $\mathrm{Ba}_{8} \mathrm{Ga}_{16} \mathrm{Ge}_{30}$ from Bentien et al. ${ }^{12}$ have been added for comparison. The electronic parts of the thermal conductivities were subtracted from the measured values using the Wiedemann-Franz relation. The low temperature crystalline peak observed for $n-\mathrm{Ba}_{8} \mathrm{Ga}_{16} \mathrm{Ge}_{30}$ is also observed in the three $\mathrm{Ba}_{8} Y_{x} \mathrm{Ge}_{46-x} \quad\left(Y_{x}=\mathrm{Ni}_{6}, \mathrm{Cu}_{6}, \mathrm{Zn}_{8}\right)$ samples. The peak is observed at approximately the same temperature for $\mathrm{Ba}_{8} \mathrm{Cu}_{6} \mathrm{Ge}_{40}$ and $\mathrm{Ba}_{8} \mathrm{Zn}_{8} \mathrm{Ge}_{38}$, whereas for $\mathrm{Ba}_{8} \mathrm{Ni}_{6} \mathrm{Ge}_{40}$ it is shifted to slightly higher temperatures. The thermal conductivity at $250 \mathrm{~K}$ is shown as function of tetrakaidecahedral cage volume in Fig. 4, and the trend is compared with the room temperature powder INS spectroscopy rattler energy $\mathrm{Ba} 2_{\text {equ }}$ and the Einstein temperature $\theta_{E, 22}$ found by multitemperature single crystal $\mathrm{x}$-ray diffraction. The energy deviation between multitemperature single crystal x-ray diffraction and the powder INS is fairly large, but the data do show the same trend with decreasing energy as the volume expands. The lattice thermal conductivity does not follow this trend. In other words the lattice thermal conductivity is determined by other factors than the cage volume or the energy of the guest atom mode. Similar Einstein temperatures for the equatorial plane motion of $\mathrm{Ba} 2_{\text {equ }}$ have been determined from SCXRD and PXRD as well as powder INS for $\mathrm{Ba}_{8} \mathrm{Cu}_{6} \mathrm{Ge}_{40}$ and $\mathrm{Ba}_{8} \mathrm{Zn}_{8} \mathrm{Ge}_{38}$, yet the lattice thermal conductivity is significantly smaller in $\mathrm{Ba}_{8} \mathrm{Zn}_{8} \mathrm{Ge}_{38}$ compared with $\mathrm{Ba}_{8} \mathrm{Cu}_{6} \mathrm{Ge}_{40}$. Presumably, the effect of site mass difference scattering on the thermal conductivity is minor in $\mathrm{Ba}_{8} \mathrm{Ni}_{6} \mathrm{Ge}_{40}$ and $\mathrm{Ba}_{8} \mathrm{Cu}_{6} \mathrm{Ge}_{40}$ since $\mathrm{Ni}$ and $\mathrm{Cu}$ are ordered on the $6 c$ position. The effect is also reduced in $\mathrm{Ba}_{8} \mathrm{Zn}_{8} \mathrm{Ge}_{38}$ due to the similar masses of $\mathrm{Zn}$ and $\mathrm{Ge}$.

$\mathrm{Ba}_{8} \mathrm{Ni}_{6} \mathrm{Ge}_{40}$ has the smallest cage volume and the highest rattler energy found both by diffraction and INS spectroscopy. Therefore $\mathrm{Ba}_{8} \mathrm{Ni}_{6} \mathrm{Ge}_{40}$ would be expected to have the highest lattice thermal conductivity because it has been argued that low thermal conductivity is linked to low Einstein energies and oversized cages. This is not observed. On the other hand $\mathrm{Ba}_{8} \mathrm{Ni}_{6} \mathrm{Ge}_{40}$ has the largest temperature indepen- 


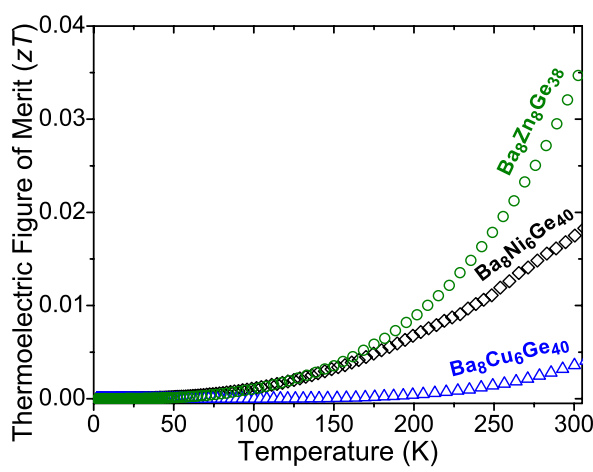

FIG. 11. (Color online) The dimensionless thermoelectric figure of merit, $z T$, for $\mathrm{Ba}_{8} \mathrm{Ni}_{6} \mathrm{Ge}_{30}$ (diamonds), $\mathrm{Ba}_{8} \mathrm{Cu}_{6} \mathrm{Ge}_{30}$ (triangles), and $\mathrm{Ba}_{8} \mathrm{Zn}_{8} \mathrm{Ge}_{38}$ (circles).

dent disorder value $(d)$ extracted from the Einstein fit to the ADPs, and furthermore the peak in the powder INS spectra is significantly broader than for the other samples $\mathrm{Ba}_{8} Y_{x} \mathrm{Ge}_{46-x}$. Similar broadening is observed for the $\mathrm{Sr}_{8} \mathrm{Ga}_{16} \mathrm{Ge}_{30}$ INS spectra, and the $d$ value is also larger for $\mathrm{Sr}_{8} \mathrm{Ga}_{16} \mathrm{Ge}_{30}$ than for $\mathrm{Ba}_{8} \mathrm{Ga}_{16} \mathrm{Ge}_{30} \cdot{ }^{11}$ The INS features and the large disorder could point to a higher degree of anharmonicity in $\mathrm{Ba}_{8} \mathrm{Ni}_{6} \mathrm{Ge}_{40}$ compared with the other $\mathrm{Ba}_{8} Y_{x} \mathrm{Ge}_{46-x}$ samples, despite the smaller cage volume. The temperature profile of $\mathrm{Ba}_{8} \mathrm{Ni}_{6} \mathrm{Ge}_{40}$ depends on synthesis conditions since glasslike temperature profiles of the thermal conductivity have been reported for $p$-type $\mathrm{Ba}_{8} \mathrm{Ni}_{6} \mathrm{Ge}_{40} \cdot{ }^{33}$

Chemical pressure has been investigated in other systems such as $\mathrm{Sr}_{8} \mathrm{Ga}_{16} \mathrm{Si}_{30-x} \mathrm{Ge}_{x}$ and $\mathrm{Ba}_{8} \mathrm{Ga}_{16} \mathrm{Si}_{30-x} \mathrm{Ge}_{x}$. ${ }^{17,18,34}$ For $\mathrm{Sr}_{8} \mathrm{Ga}_{16} \mathrm{Si}_{30-x} \mathrm{Ge}_{x}$ the lattice thermal conductivity at $15 \mathrm{~K}$ was observed to increase with increasing $\mathrm{Si}$ content. This could be correlated with the Einstein temperature from heat capacity and the volume for the guest atom. ${ }^{17}$ In a similar study of $\mathrm{Ba}_{8} \mathrm{Ga}_{16} \mathrm{Si}_{x} \mathrm{Ge}_{30-x}$ by Martin et al. ${ }^{34}$ no effect of volume was observed, nor did they see any effect of mass difference scattering. However, a recent report of $\mathrm{Ba}_{8} \mathrm{Ga}_{16} \mathrm{Si}_{x} \mathrm{Ge}_{30-x}$ grown by the Czochralski method provided evidence for strong mass difference scattering, whereas no clear effect of cage expansion was observed. ${ }^{18}$

The $z T$ values for the three compounds are shown in Fig. 11. The room temperature $z T$ values are not especially high being 0.018 for $\mathrm{Ba}_{8} \mathrm{Ni}_{6} \mathrm{Ge}_{30}, 0.004$ for $\mathrm{Ba}_{8} \mathrm{Cu}_{6} \mathrm{Ge}_{40}$, and 0.035 for $\mathrm{Ba}_{8} \mathrm{Zn}_{8} \mathrm{Ge}_{38}$. For $\mathrm{Ba}_{8} \mathrm{Zn}_{7.7} \mathrm{Ge}_{38.3}$ MelnychenkoKoblyuk et $a l .{ }^{28}$ reported a similar $z T$ at room temperature. Christensen and Iversen ${ }^{21}$ grew a $\mathrm{Ba}_{8} \mathrm{Zn}_{8} \mathrm{Ge}_{38}$ sample using a zinc flux method. This sample had a comparable thermal conductivity of $1.4 \mathrm{~W} / \mathrm{K} \mathrm{m}$ at $250 \mathrm{~K}$, but the Seebeck and electrical resistivity showed semiconducting temperature dependence. Thermoelectric properties of $\mathrm{Ba}_{8} \mathrm{Cu}_{6} \mathrm{Ge}_{40}$ and $\mathrm{Ba}_{8} \mathrm{Ni}_{6} \mathrm{Ge}_{30}$ grown with $\mathrm{Ba}_{6} \mathrm{Ge}_{25}$ as precursor have been reported by Johnsen et al. ${ }^{19,27}$ There the $\mathrm{Ba}_{8} \mathrm{Cu}_{6} \mathrm{Ge}_{40}$ sample was also found to have semiconducting properties with rather low $z T$ values, whereas $\mathrm{Ba}_{8} \mathrm{Ni}_{6} \mathrm{Ge}_{40}$ reached a reasonable $z T$ value of 0.13 at $400 \mathrm{~K}$. In comparison $z T$ for $\mathrm{Ba}_{8} \mathrm{Ga}_{16} \mathrm{Ge}_{30}$ varies between 0.04 and 0.25 at $300 \mathrm{~K}$ and peaks above unity in the interval of $700-1100 \mathrm{~K} .^{35-38}$ Tuning of the period 4 element content appears to be crucial for the optimization of the thermoelectric properties of $\mathrm{Ba}_{8} Y_{x} \mathrm{Ge}_{46-x}$ $\left(Y_{x}=\mathrm{Ni}_{6}, \mathrm{Cu}_{6}, \mathrm{Zn}_{8}\right)$.

\section{CONCLUSION}

By chemical substitution of period 4 elements in $\mathrm{Ba}_{8} Y_{x} \mathrm{Ge}_{46-x}\left(Y_{x}=\mathrm{Ni}_{6}, \mathrm{Cu}_{6}, \mathrm{Zn}_{8}\right)$ type I clathrates a chemical pressure effect has been obtained. The influence of chemical pressure on the physical properties was compared with results from measurements under applied physical pressure. The energy of the guest atom mode is influenced by the volume available for the guest atoms, but differences in guest atom chemical environment also play a crucial role. Einstein temperatures extracted from single crystal $\mathrm{x}$-ray diffraction data appear to follow the same trend of the rattler energy as found by powder INS. However, the lattice thermal conductivity is not related to the rattler energy in a simple way. $\mathrm{Sr}_{8} \mathrm{Ga}_{16} \mathrm{Ge}_{30}$ and $\mathrm{Ba}_{8} \mathrm{Ni}_{6} \mathrm{Ge}_{40}$ were both found to have broad powder INS peaks and large disorder parameters for the guest atoms in the large cage, which suggests larger disorder or anharmonicity for the $\mathrm{Sr}$ and $\mathrm{Ba}$ guest atoms in these structures compared with $\mathrm{Ba}$ in $\mathrm{Ba}_{8} \mathrm{Ga}_{16} \mathrm{Ge}_{30}$. Temperature dependent powder INS spectra revealed a stronger anharmonic potential for $\mathrm{Sr}_{8} \mathrm{Ga}_{16} \mathrm{Ge}_{30}$ than in the other clathrates, while $n$ - and $p$-type $\mathrm{Ba}_{8} \mathrm{Ga}_{16} \mathrm{Ge}_{30}$ appear to have similar shapes of the anharmonic potentials.

\section{ACKNOWLEDGMENTS}

This work is based on experiments performed at the Swiss spallation neutron source SINQ, Paul Scherrer Institute, Villigen, Switzerland. The authors would like to thank Dr. Thierry Strässle and Dr. Murat Ay for assistance during the pressure experiment at PSI and Professor Mats Nygren for SPS of the samples. The study was supported by DANSCATT and the European Commission under the Sixth Framework Program through the Key Action: Strengthening the European Research Area, Research Infrastructures Contract No. RII3-CT-2003-505925.

${ }^{1}$ G. J. Snyder and E. S. Toberer, Nature Mater. 7, 105 (2008).

${ }^{2}$ G. A. Slack, CRC Handbook of Thermoelectrics (CRC Press, Boca Raton, FL, 1995), p. 407.

${ }^{3}$ C. Uher, Semicond. Semimetals 69, 139 (2001).

${ }^{4}$ K. A. Kovnir and A. V. Shevelkov, Russ. Chem. Rev. 73, 923 (2004).

${ }^{5}$ V. Keppens, D. Mandrus, B. C. Sales, B. C. Chakoumakos, P. Dai, R. Coldea, M. B. Maple, D. A. Gajewski, E. J. Freeman, and S. Bennington, Nature (London) 395, 876 (1998).

${ }^{6}$ R. P. Hermann, W. Schweika, O. Leupold, R. Ruffer, G. S. Nolas, F. Grandjean, and G. J. Long, Phys. Rev. B 72, 174301 (2005).

${ }^{7}$ M. Christensen, F. Juranyi, and B. B. Iversen, Physica B 385-386, 505 (2006).

${ }^{8}$ Y. Takasu, T. Hasegawa, N. Ogita, M. Udagawa, M. A. Avila, K. Suekuni, I. Ishii, T. Suzuki, and T. Takabatake, Phys. Rev. B 74, 174303 (2006).

${ }^{9}$ M. M. Koza, M. R. Johnson, R. Viennois, H. Mutka, L. Girard, and D. Ravot, Nature Mater. 7, 805 (2008).

${ }^{10}$ M. Christensen, A. B. Abrahamsen, N. B. Christensen, F. Juranyi, N. H. Andersen, K. Lefmann, J. Andreasson, C. R. H. Bahl, and B. B. Iversen, Nature Mater. 7, 811 (2008)

${ }^{11}$ B. C. Sales, B. C. Chakoumakos, R. Jin, J. R. Thompson, and D. Mandrus, Phys. Rev. B 63, 245113 (2001).

${ }^{12}$ A. Bentien, M. Christensen, J. D. Bryan, A. Sanchez, S. Paschen, F. Steglich, G. D. Stucky, and B. B. Iversen, Phys. Rev. B 69, 045107 (2004).

${ }^{13}$ M. Christensen, N. Lock, J. Overgaard, and B. B. Iversen, J. Am. Chem. Soc. 128, 15657 (2006).

${ }^{14}$ Y. Jiang, F. Bridges, M. A. Avila, T. Takabatake, J. Guzman, and G. Kurczveil, Phys. Rev. B 78, 014111 (2008).

${ }^{15}$ V. Keppens, B. C. Sales, D. Mandrus, B. C. Chakoumakos, and C. Laermans, Philos. Mag. Lett. 80, 807 (2000). 
${ }^{16}$ M. A. Avila, K. Suekuni, K. Umeo, H. Fukuoka, and T. Takabatake, Phys. Rev. B 74, 125109 (2006).

${ }^{17}$ K. Suekuni, M. A. Avila, K. Umeo, and T. Takabatake, Phys. Rev. B 75, 195210 (2007).

${ }^{18}$ M. Christensen, S. Johnsen, M. Søndergaard, J. Overgaard, H. Birkedal, and B. B. Iversen, Chem. Mater. 21, 122 (2009).

${ }^{19}$ S. Johnsen, A. Bentien, G. K. H. Madsen, B. B. Iversen, and M. Nygren, Chem. Mater. 18, 4633 (2006).

${ }^{20}$ J. Rodriguez-Carvajal, FULlProF, Version 4.00, ILL, France, 2007.

${ }^{21}$ M. Christensen and B. B. Iversen, J. Phys.: Condens. Matter 20, 104244 (2008).

${ }^{22} \mathrm{G}$. M. Sheldrick, SAINT-PLUS, SADABS, and SHELX programs, Bruker AXS Inc., Madison, WI, 2003.

${ }^{23}$ F. Juranyi, L. Holitzner, N. Schlumpf, U. Greuter, T. Gahl, S. Janssen, J. Mesot, and R. Hempelmann, J. Neutron Res. 14, 333 (2006).

${ }^{24}$ O. Maldonado, Cryogenics 32, 908 (1992).

${ }^{25}$ A. Bentien, E. Nishibori, S. Paschen, and B. B. Iversen, Phys. Rev. B 71, 144107 (2005)

${ }^{26}$ See EPAPS Document No. E-JAPIAU-105-003907 for detailed results from the refinements of x-ray diffraction and powder in-elastic neutron scattering data. For more information on EPAPS, see http://www.aip.org/ pubservs/epaps.html.

${ }^{27}$ S. Johnsen, A. Bentien, G. K. H. Madsen, M. Nygren, and B. B. Iversen, Phys. Rev. B 76, 245126 (2007)

${ }^{28}$ N. Melnychenko-Koblyuk, A. Grytsiv, L. Fornasari H. Kaldarar, H. Mi- chor, F. Röhrbacher, M. Koza, E. Royanian, E. Bauer, P. Rogl, M. Rotter, H. Schmid, F. Marabelli, A. Devishvili, M. Doerr, and G. Giester, J. Phys.: Condens. Matter 19, 216223 (2007).

${ }^{29}$ D. Connétable, V. Timoshevskii, B. Masenelli J. Beille, J. Marcus, B. Barbara, A. M. Saitta, G.-M. Rignanese, P. Mélinon, S. Yamanaka, and X. Blase, Phys. Rev. Lett. 91, 247001 (2003).

${ }^{30}$ K. Tanigaki, T. Shimizu, K. M. Itoh, J. Teraoka, Y. Moritomo, and S. Yamanaka, Nature Mater. 2, 653 (2003).

${ }^{31}$ T. Kume, T. Fukushima, S. Sasaki, H. Shimizu, H. Fukuoka, and S. Yamanaka, Phys. Status Solidi B 244, 352 (2007).

${ }^{32}$ T. Fukushima, T. Kume, S. Sasaki, H. Shimizu, H. Fukuoka, and S. Yamanaka, Phys. Status Solidi B 244, 392 (2007)

${ }^{33}$ A. Bentien, S. Johnsen, and B. B. Iversen, Phys. Rev. B 73, 094301 (2006).

${ }^{34}$ J. Martin, G. S. Nolas, H. Wang, and J. Yang, J. Appl. Phys. 102, 103719 (2007).

${ }^{35}$ A. Saramat, G. Svensson, A. E. C. Palmqvist, C. Stiewe, E. Mueller, D. Platzek, S. G. K. Williams, D. M. Rowe, J. D. Bryan, and G. D. Stucky, J. Appl. Phys. 99, 023708 (2006).

${ }^{36}$ V. L. Kuznetsov, L. A. Kuznetsova, A. E. Kaliazin, and D. M. Rowe, J. Appl. Phys. 87, 7871 (2000)

${ }^{37}$ E. S. Toberer, M. Christensen, B. B. Iversen, and G. J. Snyder, Phys. Rev. B 77, 075203 (2008)

${ }^{38}$ J. D. Bryan, N. P. Blake, H. Metiu, G. D. Stucky, B. B. Iversen, R. D. Poulsen, and A. Bentien, J. Appl. Phys. 92, 7281 (2002). 